\title{
OS DIREITOS HUMANOS E SUAS INCONGRUÊNCIAS NO AMPARO AOS TRABALHADORES IMIGRANTES
}

\author{
Raissa Brindeiro de Araújo Torres ${ }^{1}$ \\ Pedro Adolfo Moreno da Costa Moreira ${ }^{2}$
}

\begin{abstract}
RESUMO: O texto aborda a questão das migrações voltadas para o mercado de trabalho e as condições de acessibilidade do estrangeiro nos países de destino. O problema da pesquisa consiste em verificar como é materializada a garantia dos direitos humanos aos trabalhadores imigrantes, levantando como hipótese a ocorrência de que não são assegurados os direitos humanos aos trabalhadores imigrantes, especialmente aqueles que se encontram em situação irregular no país de destino. Utiliza-se como referencial teórico o pensamento de Costas Douzinas, ocasião que é feita uma abordagem sobre os paradoxos dos direitos humanos. A pesquisa é descritiva, fazendo uso do procedimento hermenêutico.
\end{abstract}

PALAVRAS-CHAVE: direitos humanos; paradoxos; imigrantes; trabalhadores; irregulares.

\section{HUMAN RIGHTS AND THEIR INCONVENIENCES IN ACCORDANCE WITH IMMIGRANT WORKERS}

\begin{abstract}
The text addresses the issue of labor market migrations and the accessibility conditions of the foreigner in the countries of destination. The research problem is to verify how the guarantee of human rights is materialized for immigrant workers, raising the hypothesis that human rights are not guaranteed to immigrant workers, especially those who are in an irregular situation in the country of destination. It is used as theoretical reference the thought of Costas Douzinas, occasion that is made an approach on the paradoxes of the human rights.
\end{abstract}

KEYWORDS: human rights; paradoxes; immigrants; workers; irregular.

\section{Introdução}

A partir da integração econômica, em boa parte forçada, imposta e esquematizada pelo liberalismo, formou-se o dinamismo proposto pela globalização, o que fez com que as disparidades entre os países pesassem sobre aqueles menos favorecidos, que não conseguiam alcançar o mesmo ritmo de desenvolvimento. Nesse cenário, não se pode olvidar os impactos gerados na gestão dos fluxos migratórios internacionais e, por sua vez, no poder de regulação destes últimos pelos Estados, levando em consideração que a economia globalizada

\footnotetext{
${ }^{1}$ Doutoranda no Programa de Pós-Graduação em Ciências Jurídicas (PPGCJ-UFPB). Mestre em Direito e Desenvolvimento Sustentável no Programa de Pós-Graduação em Direito (PPGD-UNIPÊ). E-mail: raissabrindeiro@hotmail.com.

${ }^{2}$ Mestrando em Direito e Desenvolvimento Sustentável no Programa de Pós-Graduação em Direito (PPGDUNIPÊ). Especialista em Direito Tributário pela LFG. Especialista em Prática Judicante pela ESMA/UEPB. PósGraduado pela Escola Superior de Magistratura Des. Moacyr Carneiro. Registrador de Imóveis na Comarca de Seabra/BA. E-mail: pedro.pedroadolfo@gmail.com.
} 
desenvolveu uma nova estrutura industrial, razão pela qual se remanejam as fontes materiais e de mão de obra, fazendo surgir diferentes políticas laborais e movimentos de capital financeiro, alterando a disposição e o funcionamento dos mercados de trabalho, sendo imperioso adequá-los aos hodiernos padrões de competição internacional.

As migrações internacionais podem ocorrer por diferentes motivos, sendo algumas espontâneas ou voluntárias e outras forçadas. Os deslocamentos são também diferenciados pela questão da permanência nos lugares de destino, haja vista que existem movimentos temporários, que atendem às expectativas transitórias, ou definitivos, a depender dos fatores e circunstâncias que impulsionam as migrações. Ademais, as formas de migração podem ser regulares, observados os trâmites legais, ou clandestinas e irregulares. A partir do descobrimento da América, e posteriormente, por meio dos fluxos migratórios ocorridos no século XIX, tem se evidenciado que os deslocamentos populacionais são compostos, em sua grande maioria, por pessoas que buscam em outros países a saída para as condições de pobreza e miserabilidade, intensificando-se as migrações laborais.

Ademais, aqueles que se deslocam em busca de trabalho, o fazem com o intuito de satisfazerem não apenas as necessidades de ordem econômica, como igualmente anseiam por uma melhor qualidade de vida, que os façam sentir-se acolhidos pela sociedade de destino. Ocorre que, a realidade econômica e social atual, em que perdura a degradação dos salários e a mecanização da força produtiva, impacta na forma de exclusão social e enfraquecimento dos postos de trabalho - tomados pelo capital transnacional. Assim, da maneira como o capitalismo vem se desenvolvendo, o mercado se mostra cada vez mais competitivo e com olhos voltados para a maximização dos ganhos, razão pela qual, por muitas vezes, os trabalhadores imigrantes são vistos como mão de obra barata e vulnerável à exploração.

Esse artigo aborda a questão das migrações voltadas para o mercado de trabalho, assim como as condições de acessibilidade do estrangeiro nos países de destino, tendo como objeto de estudo as fragilidades quanto a materialização dos direitos humanos aos trabalhadores imigrantes. Dessa forma, o problema da pesquisa consiste em verificar como é materializada a garantia dos direitos humanos aos trabalhadores imigrantes, levantando como hipótese a ocorrência de que não são assegurados os direitos humanos aos trabalhadores imigrantes, especialmente aqueles que se encontram em situação irregular no país de destino, por não estarem abrangidos no grupo de pessoas que fazem parte da "humanidade". Tal abordagem se faz à luz das normas e princípios internacionais de direitos humanos, e utilizase como referencial teórico o pensamento de Costas Douzinas, ocasião em que é feita uma 
abordagem sobre os paradoxos dos direitos humanos. Por fim, em relação ao recorte metodológico, a pesquisa é descritiva, fazendo uso do procedimento hermenêutico.

O texto encontra-se organizado de forma a se desenvolver na sequência que aqui se coloca: breve histórico das migrações laborais; trabalhadores imigrantes e a garantia dos direitos humanos; direitos humanos como fruto da época moderna: fragilidades quanto à sua materialização.

\section{Breve histórico das migrações laborais}

O progresso técnico dos meios de transporte que facilitaram os deslocamentos internacionais na segunda metade do século XIX, período em que ocorreu a Segunda Revolução Industrial, receberam um forte aliado na intensificação dos movimentos migratórios, qual seja, os sistemas de telecomunicação, que além de promoverem a celeridade na divulgação das informações, fizeram com que normas e valores fossem internacionalizados, "possibilitando a diferentes povos a redefinição de padrões e aspirações de comportamento e, portanto, a construção de um imaginário sobre a realidade do seu e de outros países" (BRITO, 1995, p. 31), criando a chamada "ilusão migratória" que contribuiu para motivar a migração e a esperança de melhores condições sociais e econômicas.

Ademais, a globalização econômica iniciada no final do século $\mathrm{XX}$, tendo como marco a Revolução Industrial, compeliu os países a seguirem "as mesmas regras do jogo e a submeter-se aos fiscais internacionais" (MARTINE, 2005, p. 4), formando-se uma nova organização econômica global. Nessa expedição em busca de capital financeiro e maximização dos lucros, as migrações entram em cena, haja vista que, ressalvadas as ocorrências de desastres naturais, conflitos religiosos e armados, "a globalização é o principal fator que ativa os movimentos migratórios entre países e determina seus contornos" (MARTINE, 2005, p. 8).

Considerando-se a história mais remota, observa-se que, até meados do século XX período este caracterizado pelas grandes colonizações - a migração concentrava-se na população europeia. Esta, em busca de condições de vida mais próspera e digna, se deslocava com destino às terras do "novo mundo". Destaque-se, sobre essa etapa da História, a vinda dos europeus para o Brasil, motivados pela crise econômica e os horrores das guerras, esperançosos de encontrar maior facilidade na obtenção de subsistência material, conquanto 
alguns - ao que a própria História relata - viessem também à cata de aventuras.

Importante registrar que o excedente demográfico, gerado pelo acelerado processo de industrialização, somado a crise econômica e inconstância política na Europa, teve como saída os deslocamentos populacionais, que foram facilitados pela necessidade de mão de obra nos países pouco desenvolvidos. Por outro lado, após a Primeira Guerra Mundial (19141918), despontou um grande número de apátridas, sem nacionalidade alguma e destituídos de seus direitos de cidadania, que peregrinavam como nômades em busca de países que os recebessem, desencadeando mais um problema político no continente europeu. No período compreendido entre as duas grandes Guerras Mundiais, também lembrado pela Revolução Russa de 1917, fruto da insatisfação da população com a monarquia Czarista, os Estados alavancaram políticas nacionalistas que, dentre outras ações afirmativas, dificultaram os movimentos populacionais, com a exigência de documentos de passaporte e visto de entrada de estrangeiros.

No avançar dos acontecimentos, a Segunda Grande Guerra (1939-1945) eclodiu com propósitos de aniquilação de povos inimigos, escravização e subjugação daqueles considerados seres inferiores, marcada pelos regimes totalitários, deixando a humanidade visivelmente abalada, tendo o capitalismo se difundido posteriormente em torno das duas grandes potências hegemônicas, Estados Unidos e União Soviética, que defendiam uma nova forma de expansionismo econômico, a qual fez ressoar uma divisão internacional do trabalho ordenada por fluxos migratórios internacionais que impulsionaram os deslocamentos dos mexicanos para a América do Norte, e no continente europeu, assistiu-se a movimentos populacionais de portugueses, espanhóis, gregos, turcos, finlandeses, iugoslavos e irlandeses em direção aos países mais desenvolvidos, notadamente Alemanha, Inglaterra, Suíça e França (BRITO, 1995, p. 26).

Com o fim da Segunda Guerra Mundial, a Europa abriu espaço para os imigrantes, tendo em vista as baixas taxas de crescimento populacional, e a escassez de mão de obra, em um momento em que os países, ao passo que buscavam reerguer-se dos destroços causados pela guerra, vivenciavam a expansão econômica, razão pela qual o trabalhador estrangeiro foi ocupando espaço no meio de produção capitalista. A princípio, as migrações laborais eram realizadas através de agências de contratação, que negociavam junto aos países que necessitavam de força de trabalho barata e flexível (PALACIOS BAÑUELOS, 2012, p. 37).

A definição de trabalhador migrante foi normatizada em 1925, por ocasião do Congresso Internacional do Trabalho em Roma, passando a englobar todas as pessoas que 
saem de seus países de origem em busca de trabalho em outras localidades, como aconteceu com os camponeses no contexto do capitalismo agrário do século XIX, quando deixaram o ambiente rural e passaram a ocupar as cidades europeias, chegando muitos a migrar para países localizados no continente americano (PALACIOS BAÑUELOS, 2012, p. 31).

Não se pode deixar de observar que os movimentos migratórios sofrem interferência provenientes das diretrizes impostas pelos sistemas financeiros, que cada vez mais cobram por mão de obra qualificada, capaz de atender aos investimentos econômicos, em escala global. Nessas condições, embora as distâncias territoriais não se mostrem mais como empecilho à intercomunicação entre os povos, principalmente com os meios de comunicação e avanços tecnológicos que se renovam e se atualizam a cada dia, as aspirações do mundo globalizado e competitivo, acabam por selecionar aquelas pessoas que melhor atendem às necessidades do mercado capitalista, excluindo uma parcela da população, ficando esta marginalizada e impossibilidade de usufruir de seus direitos fundamentais, em igualdade de condições com as demais.

Em verdade, o fenômeno migratório, em sua própria essência, perpassa os valores de identidade daquele que deixa seu lugar de origem para buscar melhores condições de vida, sendo imperioso abrir espaço para o debate social em busca de soluções para a falta de amparo ao imigrante, reconhecida a sua condição de vulnerabilidade.

Além disso, as políticas migratórias adotadas pelos países receptores de imigrantes, em sua maioria, tendem a robustecer as exigências impostas para a concessão de vistos de trabalho, de forma a direcionar as permissões de ingresso para aqueles imigrantes que apresentam melhores qualidades profissionais e que sirvam para preencher as lacunas do mercado, sem considerar as necessidades humanas dos que procuram viver e trabalhar no país. Em meio a essa ciranda de interesses econômicos, surge a preocupação com aqueles que, não se enquadrando no modelo padrão exigido pelo mercado laboral, encontram-se em condições irregulares, trabalhando em atividades pouco valorizadas e com baixa remuneração, cenário propício para diversos casos de exploração laboral.

\section{Trabalhadores imigrantes e a garantia dos direitos humanos}

Nas tendências da nova era de migrações, os diferentes abusos sofridos pelos migrantes, quer seja em trânsito, quer seja quando se encontram reféns de contrabandistas e 
traficantes, costumam trazer consequências irreparáveis, como é o caso da frequente exploração laboral e das reações xenófobas de alguns grupos populacionais. Por sua vez, não se pode deixar de mencionar as tensões sociais e culturais, quando o estrangeiro possui tradições ou crenças incompatíveis ou de difícil assimilação para os nacionais.

Ao que se observa, a postura dos Estados receptores - e por que não dizer - a frequente reação dos nacionais de tais Estados, não são consentâneas com os preceitos das diversas Declarações Internacionais que pretendem estabelecer um padrão civilizatório para os Estados no que diz respeito aos direitos fundamentais. Destas, vale destacar a Declaração do Milênio (ONU, 2000), em cujo Preâmbulo se encontra grafado o compromisso dos Estados em adotar medidas para assegurar a proteção dos direitos humanos dos trabalhadores migrantes e seus familiares, tendo como objetivo promover a harmonia e a tolerância nas sociedades. De igual forma, o Preâmbulo do documento referido considera o compromisso dos Estados em "[...] trabalhar coletivamente para conseguir que os processos políticos sejam mais abrangentes, de modo a permitirem a participação efetiva de todos os cidadãos, em todos os países".

Ainda no que se refere à proteção buscada pela orientação internacional das Declarações universais, na Declaração Universal dos Direitos Humanos (ONU, 1948), baliza dos direitos humanos na contemporaneidade, a pessoa humana é assentada como foco, respeitando o princípio da dignidade humana e os valores democráticos da sociedade, que buscam o bem-estar social e a garantia dos direitos fundamentais de todos. Contudo, muito embora os discursos recentes considerem que o mundo esteja interligado, formando uma espécie de "aldeia global", haja vista que as facilidades tecnológicas, de transporte e comunicação ultrapassam os limites espaços-temporais, uma parcela de pessoas vive despojada de seus direitos inalienáveis, em razão da dificuldade de inclusão na sociedade, como estar-se-á a tratar dos migrantes que arriscam suas vidas à procura de sobrevivência, longe de seus lugares de origem.

Por assim dizer, um empecilho a ser superado diz respeito à integração do imigrante na comunidade de destino, questão esta que não depende apenas de esforços do estrangeiro, mas sobretudo exige um compromisso da sociedade civil como um todo. Nessas condições, o Governo deve articular planos de ação que facilitem a inclusão do imigrante, concedendo-lhe todas as garantias de direitos humanos, em atenção especial para aqueles que se encontram em condições ilegais, os quais estão mais propícios a sofrer abusos.

Nessas condições, a questão toma maiores proporções, não só em função do 
tratamento indiferente prestado aos deslocados populacionais, como também pela forma pejorativa como são reconhecidos nos países de destino, sendo frequentes as situações em que os Estados tentam impedir a inclusão do estrangeiro, utilizando como subterfúgio a incidência da criminalidade, o que acaba criando condições de rejeição em razão de estereótipos imaginados.

Nos tempos atuais, vivencia-se a explosão do multiculturalismo que, por sua vez, não se enquadra no modelo tradicional de cultura homogênea ligada à nação. Assim sendo, nas sociedades pluralistas, em que se misturam diferentes culturas, tradições e costumes - fruto da miscigenação dos grupos étnicos - a preocupação com a integração social ganha destaque. No pensamento de Habermas, (2002, p. 136) a força integrativa do Estado só alcançará a cidadania democrática, com vigores a promover a solidariedade entre estranhos, "quando der mostras de sua eficiência enquanto mecanismo pelo qual os pressupostos constitucionais das formas de vida desejadas possam de fato tornar-se realidade".

Na verdade, o grande desafio consiste na efetivação dos direitos humanos, haja vista que "os direitos (supostamente) iguais foram apenas gradativamente estendidos aos grupos reprimidos, marginalizados e excluídos” (MERCOSUL E AS MIGRAÇOES, 2008, p. 34). Com efeito, deve-se ter como norte os ideais de igualdade, fazendo-se necessário compreender que o tratamento dispensado ao imigrante - ainda que seja este carente dos vínculos de nacionalidade e cidadania - deve ser paritário com o dispensado aos nacionais.

Sobre a igualdade, o termo foi ganhando acepção mais específica, mais voltada para a dignidade do homem, com a evolução do valor ético-social nas sociedades, notadamente no Ocidente. Assim, a expressão desse conceito novo se afirma através de documentos internacionais, primeiro enquanto igualdade formal, também entendida como igualdade perante a lei, que despontou no período das Revoluções burguesas, nomeadamente a partir da Revolução Francesa. Com efeito, a Declaração dos Direitos do Homem e do Cidadão, de 1789, provavelmente o documento interno (documento do Estado francês) que mais espraiou seus princípios para todo o mundo, primou pela garantia das liberdades fundamentais e pela supressão de privilégios e imunidades que revestiam o regime anterior, no intuito de promover os ideais de igualdade jurídica aplicada a todos indistintamente.

É essa ideia que se depreende do artigo $1^{\circ}$ do referido documento, a qual se refere Pérez Luño (2005, p. 19) quando pontua a igualdade formal como aquela que “[...] suele identificase con la exigencia jurídico política sintetizada en el principio de la igualdad ante la 
ley". O autor complementa seu pensamento afirmando que o referido principio "[...] supone el reconocimiento de un mismo estatuto jurídico para todos los ciudadanos, lo que implica la garantía de la paridad de trato en la legislación y en la aplicación del derecho”. Dessa forma, a igualdade formal, também conhecida como princípio da isonomia, que teve seu berço no Estado Liberal, e foi introduzida em diversos documentos nacionais e internacionais, não mais se apoia sozinha, tendo em vista que as sociedades carregaram ao longo do tempo diferentes formas de desigualdades, que só podem ser superadas por meio da materialização da igualdade.

Ademais, os direitos de igualdade, por seu caráter universal, aplicam-se, por óbvio, as condições de integração dos imigrantes nas sociedades de destino. Nesse sentido, o Relatório da Comissão Mundial sobre as Migrações Internacionais (2005, p. 45) atenta para a responsabilidade dos Estados em promover a inclusão social e a equiparação de direitos. De acordo com o referido documento, "os Estados têm a responsabilidade de providenciar aos migrantes autorizados um estatuto legal seguro e a documentação apropriada, e assegurar-lhes que podem exercer todos os seus direitos humanos". Afirma ainda que "[...] os Estados devem agir de modo igualmente firme contra quaisquer elementos da sociedade que procurem abusar, intimidar ou explorar os migrantes. Se estes objetivos básicos não forem atingidos, a integração será problemática".

Como bem aduz Santos (2010, p. 294), as políticas de imigração "foram sempre determinadas em função da integração pelo trabalho e, portanto, sempre vulneráveis às variações do mercado de trabalho". Dessa forma, a concretização do princípio da igualdade, não é algo assegurado nos processos migratórios. Em geral, eles se fazem segundo a lógica da seleção, sendo melhor aceitos nos países de destino os migrantes que possuem maior qualificação e que apresentem um elevado potencial de rentabilidade para a economia. Segundo Martine (2005, p. 16), além desse processo, evidenciam-se riscos como “[...] problemas de adaptação, discriminação e até maltrato de migrantes", situações que ocorrem com frequência. Os imigrantes “[...] sofrem discriminação social e racial, são tratados como cidadãos de segunda classe, são perseguidos e maltratados por xenófobos". Essa conjuntura, sabe-se, apenas pode ser mudada pela concretização do princípio da igualdade, tendo em vista que só as políticas que induzam a essa efetivação conseguem levar aos imigrantes as condições de preenchimento de suas necessidades básicas de saúde, moradia, lazer, educação e trabalho, em conformidade com os valores de dignidade inerentes a todo ser humano. 
Por sua vez, suporte consistente para o tratamento igualitário aos trabalhadores imigrantes é abordado nos estudos das teorias e da aplicação do princípio da solidariedade. Importante destacar que a busca pela afirmação do princípio da solidariedade surge do contexto da percepção de uma acelerada individualização dos sujeitos, fazendo com que a consciência atual se atente aos desenvolvimentos socioculturais que, além de promoverem a liberalização das expectativas de rol tradicionais e ampliarem os espaços de jogos entre os indivíduos, acabam por ocasionar a erosão cultural dos meios sociais que geram a comunidade.

\section{Direitos humanos como fruto da época moderna: fragilidades quanto à sua materialização}

Os direitos humanos surgem como a salvação para toda a opressão, guerra e dominação decorrente das duas grandes guerras mundiais, sendo a última de tamanha atrocidade, deixando o mundo totalmente devastado. Em um mundo globalizado, pode-se compreender os direitos humanos como um ideal a ser utilizado em discursos de direita e de esquerda, carregado de ideais revolucionários que resolveriam os problemas da humanidade.

O Direito Internacional dos Direitos Humanos, que ganhou destaque no período que sucedeu a Segunda Guerra Mundial, trouxe para a humanidade a esperança de reconstruir os direitos humanos devastados pela guerra, sendo imperioso destacar a Convenção de Viena sobre os Direitos dos Tratados de 1969, que regula as relações entre os Estados, considerando nulos os tratados firmados entre os Estados que venham a conflitar com a norma de Direito Internacional. Mas o que se tem observado é que, quanto mais avançado o processo de individualização, maior a probabilidade do sujeito singular se inserir em uma rede mais densa e mais sutil de anonimato, carente de proteção recíproca. Sendo assim, as mudanças de condições sociais tomaram fôlego no período da pós-modernidade, celebrando-se um acelerado processo de pluralização das orientações de vida do indivíduo como resultado da superação dos princípios morais universalistas.

Buscando melhor entender a finalidade dos direitos humanos, e como eles são aplicados na realidade, o autor Costas Douzinas (2009, p. 21) faz um estudo pormenorizado sobre o tema, de maneira a encontrar resposta para os seguintes questionamentos:

Qual trajetória histórica conecta o Direito Natural clássico aos direitos humanos? 
Que circunstâncias históricas levam à emergência dos direitos naturais, e mais tarde, dos direitos humanos? Quais são as premissas filosóficas do discurso dos direitos? Quais são hoje a natureza, a função e a ação dos direitos humanos, de acordo com o liberalismo e seus muitos críticos filosóficos? São os direitos humanos uma forma de política? São eles a resposta pós-moderna ao esgotamento das majestosas teorias e grandiosas utopias políticas da modernidade?

Para o autor (DOUZINAS, 2009, p. 20), de início, os direitos humanos surgem para satisfazer interesses da burguesia, sendo utilizados como instrumento de combate ao despotismo, carregado de pensamentos de igualdade e liberdade, com aspirações de que "o poder político deve estar sujeito às exigências da razão e da lei”. Essas ideias ganharam impulso e acabaram por ensejar uma das mais influentes ideologias da sociedade contemporânea, colocando em destaque a democracia liberal, e os compromissos com a emancipação humana, em uma esfera de alcance universal.

$\mathrm{O}$ que se mostra curioso, e porque não dizer, paradoxal, é que o mesmo século XX utilizado como marco para os direitos humanos, e suas propostas iluministas, é marcado por uma avalanche de atrocidades, onde o massacre e o genocídio aniquilou muitos povos, acentuando as disparidades entre ricos e pobres, e levando a acreditar que os pensamentos revolucionários não passavam de uma ideologia que não se coadunava com o cenário de desastre, separação e dicotomia do século.

Além disso, paira a dúvida se os direitos humanos marcam apenas um momento vivido nos dias hodiernos, até que se alcance o modelo civilizatório almejado, ocasião em que a ideologia perderá seu sentido, sendo então uma etapa a ser superada. Para compreender os seus propósitos, é acertado despir-se de toda e qualquer concepção já formada e tida como verdadeira e incontestável, o que em nenhum momento significa abraçar a bandeira do “inumano, anti-humano e do mal”, como bem destaca Douzinas (2009, p. 26), mas sim tentar, ainda que não seja tarefa das mais fáceis, entender quando e por qual razão o direito natural passou a ser chamado de direitos humanos, cobertos pelo positivismo, onde razão e lei são as palavras de ordem e o caminho para a justiça.

Ainda fazendo uso dos apontamentos de Douzinas (2009, p. 26-27), é importante destacar dois importantes personagens que influenciaram na transformação do direito natural para os direitos humanos, quais sejam, os filósofos ingleses John Locke e Jeremy Bentham, cada um com suas representatividades:

Locke é o revitalizador moderno da tradição moribunda, ao passo que Bentham é o desmascarador definitivo de qualquer "estupidez ao quadrado" remanescente. A história condensada do Direito Natural termina com a introdução da Declaração 
Universal dos Direitos Humanos, em 1948, que transformou o "contrassenso" naturalista em direitos positivos contundentes. Pela primeira vez na história, essas ficções não escritas, inalteráveis, eternas, dadas por Deus ou racionais podem deixar de ser desconcertantes. Elas foram plenamente reconhecidas e legalizadas e desfrutam da dignidade da lei, embora de um tipo um tanto brando.

Ademais, deve-se lembrar os precedentes jurídicos da Declaração dos Direitos do Homem e do Cidadão, na França, em 1789, e a Declaração de Independência dos Estados Unidos, em 1776, ambas proclamando os direitos como inerentes a condição humana e de caráter universal, fazendo um elo de ligação entre as ideias clássicas do direito natural e as ideias modernas dos direitos humanos, como se as tradições se continuassem, fruto da evolução do pensamento.

O que não é muitas vezes observado, e acaba por passar despercebido em meio ao entusiasmo dos ideais de direitos humanos, é que seus pensamentos e articulações tem sido coordenados por grupos seletos de colunistas, diplomatas e juristas internacionais que não possuem notável conhecimento, ou melhor, não estão capacitados para lidar com as diferentes formas de violações de direitos humanos, senão através de "um discurso de legitimidade do Estado" (DOUZINAS, 2009, p. 25), fazendo com que a teoria de direitos humanos fique a cargo dos governos, instituições internacionais e poderes jurídicos, em uma verdadeira combinação “[...] de iluminismo com resignação e apatia e, com uma forte sensação de impasse político e claustrofobia existencial, de uma falta de saída no seio da mais maleável sociedade" (DOUZINAS, 2009, p. 30).

Embora a humanidade tenha evoluído de maneira a enaltecer os direitos humanos e a liberdade como valores de uma sociedade democrática e participativa, muitos problemas enfrentados no passado continuam a existir, notadamente em termos de acesso aos direitos fundamentais. No entendimento de Amartya Sen (2010, p. 32), a expansão da liberdade individual é considerada uma valiosa ferramenta de alcance do desenvolvimento, atentando-se para a questão das privações das liberdades humanas, que caso não sejam consideradas no processo de desenvolvimento, podem interferir nas capacidades das pessoas em garantir os seus direitos. Assim, a garantia das liberdades humanas é importante para o desenvolvimento, não se restringindo este último ao crescimento econômico da renda per capita, mas tendo como desafio combater as desigualdades.

Ao sustentar as dificuldades na materialização dos direitos humanos, Douzinas entende que estes últimos, só tem "paradoxos a oferecer", uma vez que "são usados como defesa do indivíduo contra um poder estatal construído à imagem de um indivíduo com 
direitos absolutos. As premissas assentadas nas Declarações francesa e americana, e que foram reproduzidas posteriormente na Declaração Universal dos Direitos Humanos, de que todos nascem livres e iguais, é a prova de que estar-se-á a falar de um ideal destoante da realidade, não podendo ser então compreendidas como declarações, propriamente ditas, mas sim normas e aspirações, posto que “[...] assim que passamos de declarações a pessoas corporificadas concretas, com gênero, raça, classe e idade, a natureza humana com sua igualdade e dignidade sai de cena rapidamente" (DOUZINAS, 2009, p. 110). Dessa forma, os direitos humanos são desenvolvidos justamente nesse espaço que separa a realidade inexistente da Declaração Universal de Direitos Humanos e a sua futura aplicação.

Sobre a ideia de humanidade, Douzinas (2009, p. 119) destaca que:

[...] podemos concluir que o "homem" das declarações é uma abstração, universal, mas irreal, uma entidade "desencarregada" despojada de suas características. Como representante da Razão, ele não tem tempo nem lugar. O cidadão, por outro lado, é sempre um "homem inglês" burkeano. Tem direitos e deveres conferidos a ele por leis do Estado e pela tradição nacional; deve ficar subordinado à lei para tornar-se sujeito da lei. [...] Para os que não têm representação, sobra muito pouco. Os semEstado, os refugiados, as minorias de vários tipos não têm quaisquer direitos humanos. Quando Estados liberais alegam ter abolido privilégios e proteger direitos universais, eles querem dizer que os privilégios foram agora estendidos a um grupo chamado coletividade e cidadãos, que corresponde ainda a uma pequena minoria.

A realidade mostra que os direitos humanos não são usufruídos por todos os seres humanos, mas apenas por uma parcela de cidadãos, desconstruindo a ideia de universalidade. Exemplo concreto pode ser percebido em relação a situação dos refugiados e imigrantes, que sofrem com a falta de amparo, por não contarem com a proteção do Estado.

Importante questão a ser valorada é a diferenciação entre os direitos humanos do homem e os direitos humanos do cidadão, como se tivessem pesos distintos. Sobre o assunto, as anotações feitas por Marx são importantes:

Observemos por um momento os assim chamados direitos humanos, mais precisamente os direitos humanos sob sua forma autêntica, ou seja, sob a forma que eles assumem entre seus descobridores, entre os norte-americanos e franceses! Esses direitos humanos são em parte direitos políticos, direitos que são exercidos somente em comunhão com os outros. O seu conteúdo é constituído pela participação na comunidade, mais precisamente na comunidade política, sob a categoria dos direitos do cidadão, os quais, como vimos, de modo algum pressupõem a superação positiva e irrefutável da religião, e portanto, inclusive por exemplo do judaísmo. Resta, então, analisar a outra parte dos direitos humanos, os droits de l'homme [direitos do homem], na medida em que são distintos dos droits du citoyen [direitos do cidadão]. 
Estudando o tema sob a perspectiva das migrações internacionais contemporâneas, ainda que os fatores que impulsionam estas sejam distintos daqueles que deram ensejo aos apátridas e minorias no momento histórico posterior a Primeira Guerra Mundial, as questões envolvendo direitos humanos e da soberania continuam em contrassenso, na medida em que a titularidade dos direitos do indivíduo não garantem a sua proteção, estando subordinada à soberania nacional (BRITO, 2013, p. 89).

Atentando para a realidade contemporânea, mas sem deixar de considerar que os frutos advindos do desenvolvimento "são utilizados para reforçar a matriz institucional herdada de uma sociedade oligárquica e escravocrata, ao invés de servir para transformá-la”, Veiga acredita que os “[...] benefícios não chegam sequer a melhorar o acesso das populações mais vulneráveis". O autor complementa dizendo que "a permanência de instituições patrimonialistas faz com que o progresso material de algumas elites seja obtido às expensas da qualidade de vida, não apenas de multidões de desvalidos amontoados nos purgatórios" (VEIGA, 2010, p. 98), sobretudo sem preocupar-se com as gerações futuras, sendo cada vez mais difícil a materialização das garantias fundamentais.

Em relação aos valores de dignidade humana, Morikawa (2012, p. 92) esclarece que o Estado tem o papel de garantir as capacidades humanas básicas, assegurando como bem maior a realização da justiça social. Assim, a autora, utilizando como fonte de pesquisa o enfoque das capacidades proposto por Nussbaum, faz uma análise do direito ao desenvolvimento sob uma perspectiva de direitos humanos, dando ênfase ao papel das instituições na garantia desses direitos em um mundo globalizado, ponderando que, ao defender o enfoque das capacidades como garantia da dignidade humana, estar-se-á relacionando o direito a uma tarefa afirmativa, o que se mostra pertinente através da atuação do Estado em prol da tutela dos direitos fundamentais.

Nesse contexto de instabilidade, o Estado tem um papel influente no processo de desenvolvimento, includente e sustentável, que vai muito além da multiplicação de riqueza material, tendo como objetivo reparar as desigualdades através de uma mudança estrutural no planejamento da economia e da sociedade, que harmonize metas sociais, ambientais e econômicas, equilibrando os diferentes aspectos da sustentabilidade (SACHS, 2008, p. 11). No entanto, mesmo existindo Declarações e Tratados Internacionais garantindo a proteção dos direitos humanos dos migrantes, ainda quando estes estejam em situação irregular no país, persiste a oposição dos Estados em cumprir os dispositivos internacionais, o que, em sua 
maioria, relaciona-se ao temor da limitação do poder soberano (LIMA, 2006, p. 249).

\section{Conclusão}

Muito embora os mecanismos internacionais de proteção dos direitos humanos estejam ampliando-se, são poucos os países que adequam suas legislações internas às normas internacionais, principalmente em relação às políticas migratórias que, de uma forma geral, fazem uso do exercício da soberania para inibirem a livre circulação de pessoas, muitas vezes promovendo excessos no controle de entrada de estrangeiros, de maneira infundada.

Além disso, levando em consideração a complexidade dos fluxos migratórios contemporâneos, os trabalhadores imigrantes que se deslocam em busca de melhores condições de vida e trabalho, necessitam de tratamento diferenciado e tutela efetiva, o que não acontece na prática, não sendo o imigrante visto como um sujeito de direitos, mas sim como mão de obra barata e vulnerável à exploração.

No presente estudo, destacou-se as incongruências existentes na afirmação dos direitos humanos, em particular, relacionadas aos trabalhadores imigrantes. Como restou demonstrado, os discursos de igualdade de direitos, não condizem com a realidade social, sendo patente as desigualdades e diferentes formas de discriminação, existindo barreiras e privilégios na sociedade que não podem ser combatidos através de políticas revestidas de caráter universal. Dessa forma, pode-se inferir que a sociedade carece de instrumentos de concretização dos direitos humanos, na medida em que estes não passam de garantias formais, revestidas de discurso liberalista individual, sem considerar os elementos que compõe a sociedade, e suas particularidades.

\section{Bibliografia}

BRITO, Fausto. A politização das migrações internacionais: direitos humanos e soberania nacional. R. bras. Est. Pop., Rio de Janeiro, v. 30, n. 1, jan./jun. 2013.

. Ensaios sobre as migrações internacionais no desenvolvimento do capitalismo.

Revista Brasileira de Estudos de População, Campinas, v. 12, n. 1-2, jan.-dez. 1995. 
COMISSÃO MUNDIAL SOBRE AS MIGRAÇÕES INTERNACIONAIS. As migrações num mundo interligado: novas linhas de ação. Trad. Elsa Oliveira e Carlos Fiuza. Lisboa: Fundação Calouste Gulbenkian, 2005.

DOUZINAS, Costas. O fim dos direitos humanos. Trad. Luzia Araújo. São Leopoldo: Unisinos, 2009.

HABERMAS, Jürgen. A inclusão do outro: estudos de teoria política. Trad. George Sperber e Paulo Astor Soethe. São Paulo: Edições Loyola, 2002.

LIMA, Firmino Alves. Os Direitos Humanos dos Migrantes. In: FREITAS JR., Antônio Rodrigues de. Direito do trabalho e direitos humanos. São Paulo: BH Editora e Distribuidora de Livros, 2006.

MARTINE, George. A globalização inacabada: migrações internacionais e pobreza no século 21. São Paulo em Perspectiva, São Paulo, v. 19, n. 3, jul./set. 2005. Disponível em: $<$ http://www.scielo.br/scielo.php?script=sci_arttext\&pid=S0102-88392005000300001\&lng= en\&nrm=iso>. Acesso em: 23 abri. 2015.

MARX, Karl. Sobre a questão judaica. Trad. Nélio Schneider. São Paulo: Boitempo, 2010.

MERCOSUL E AS MIGRAÇÕES: os movimentos nas fronteiras e a construção de políticas públicas regionais de integração. Exposições e Debates. Ministério do Trabalho e Emprego. Brasília, 2008. Disponível em: <http://www3.mte.gov.br/trab_estrang/Livro_ Mercosul_e_Migracoes.pdf>. Acesso em: 26 de maio de 2015.

MORIKAWA, Márcia Mieko. Capacitação humana para o desenvolvimento como liberdade: um diálogo com Amartya Sen e Martha Nussbaum. In: ALBUQUERQUE, Armando (coord.). Desenvolvimento: aspectos sociais, econômicos e político-criminais. Lisboa: Juruá, 2012.

ONU. Declaração Universal dos Direitos Humanos de 1948. Disponível em: <http://www.dudh.org.br/wp-content/uploads/2014/12/dudh.pdf>. Acesso em: 26 jan. 2015. 
. Programa das nações unidas para o desenvolvimento. Declaração do milênio.

Disponível em: <http://www.pnud.org.br/Docs/declaracao_do_milenio.pdf>. Acesso em: 03 mar. 2015.

PALACIOS BAÑUELOS, Luis. Las migraciones internacionales desde una perspectiva histórica. In: CANO LINARES, Maria Ángeles (dir.). Migraciones internacionales en el espacio iberoamericano del siglo XXI. Madrid: Dykinson, 2012.

PÉREZ LUÑO, Antonio Enrique. Dimensiones de la igualdad. Madrid: Dykinson, 2005.

SACHS, Ignacy. Desenvolvimento: includente, sustentável, sustentado. Rio de janeiro: Garamond, 2008.

SANTOS, Boaventura de Sousa. A construção intercultural da igualdade e da diferença. In: A gramática do tempo: para uma nova cultura política. São Paulo: Cortez, 2010.

SEN, Amartya. Direito como liberdade. Trad. Laura Teixeira Motta. São Paulo: Companhia das letras, 2010.

VEIGA, José Eli da. Desenvolvimento sustentável: o desafio do século XXI. Rio de Janeiro: Garamond, 2010. 